\title{
CORRESPONDENCE
}

\section{Differing opinion, not misconduct}

It greatly concerns us that the reputation of one of our faculty, cancer-vaccine researcher Nina Bhardwaj, was called publicly into question through your premature publication of fired researcher David O'Neill's allegations of research misconduct (Nature 467, 260; 2010), particularly as the New York University School of Medicine (NYU) was not then in a position to comment. The investigation by the NYU inquiry committee is now complete and Bhardwaj's reputation is restored.

The committee investigated each of O'Neill's allegations, reviewing relevant documents and drafts of manuscripts, interviewing the individuals involved, and engaging an outside expert statistician to review the allegations and documents. Neither the committee nor the independent expert found any credible evidence to support the allegations (for details, see go.nature.com/gxhfml).

Before O'Neill's employment was terminated (which was not in retaliation for reporting alleged misconduct as he said), the other co-authors of the manuscript about which he had complained convened to address his disagreement with the method of statistical analysis used. The dispute was resolved by including three different statistical methodologies in the manuscript, which reported on the outcome of an exploratory clinical trial. Each of these came to the same conclusion namely, that the dendritic-cell vaccine developed by Bhardwaj is inferior to vaccine delivered by mineral-oil adjuvant.

The committee found no credible evidence that Bhardwaj was motivated, financially or otherwise, to "spin" the results of the trial to promote the dendritic-cell vaccine. Along with the independent expert, they concluded that the statistical tests were selected by the director of NYU's biostatistics division, not by Bhardwaj, and that the disagreement constituted a difference of opinion, not research misconduct. This difference arose because Bhardwaj and the other co-authors gave greater weight to the opinion of the statistical experts than to O'Neill on the matter of statistical method.

Bhardwaj's standing has therefore been upheld as a valued member of our faculty, as a committed mentor to junior faculty members and as a highly esteemed researcher in the cancer-vaccine field.

Steven B. Abramson New York University School of Medicine, USA. stevenb.abramson@nyumc.org

\section{Stuttering studies support treatment}

We take issue with some of Peter Howell's statements about stuttering (Nature 470, 7; 2011).

Most of these relate to the

Lidcombe programme for reducing stuttering, which we developed with colleagues at the Australian Stuttering Research Centre at the University of Sydney. Statements about the efficacy of the treatment are based on research data, not belief — as Howell implies.

We dispute his claim that there are insufficient data to support firm conclusions about the treatment. There are more than ten peer-reviewed journal reports evaluating the treatment positively, including a randomized controlled trial of 54 children published in 2005 in the British Medical Journal, and an independent, randomized study of 46 German children. A metaanalysis of randomized, controlled evidence for the treatment of 145 children, to be published in the Handbook of Evidence-Based Practice in Clinical Psychology
(Wiley, in the press), shows that those who receive it have 7-8 times greater odds of attaining satisfactory clinical outcomes than those who do not.

We are insulted that Howell likens the procedures used in the treatment to training a dog, given the extensive literature about the use of verbal operant procedures (such as reward and punishment) in many aspects of clinical psychology and education. His view is that the results of our clinical trial could be skewed because we consider that repeated words (not just syllables) can constitute stuttering. The World Health Organization makes no such exclusion.

With regard to auditory feedback devices, we would like to point out that a clinical trial has shown no treatment effect in real-life situations (R. Pollard et al. J. Speech Lang. Hear. Res. 52, $516-533 ; 2009)$. It seems to us that Howell also underestimates the incidence of stuttering. A prospective study published in 2009 in Pediatrics of a cohort of 1,619 children (ascertained before the onset of stuttering) reported a cumulative incidence of stuttering at age 3 years of $8.5 \%$.

A prospective longitudinal study of 147 stuttering children in 1999 also showed that the severity of stuttering in children younger than 6 years did not predict lifelong stuttering. We therefore disagree with Howell's view that parents should be told whether a child's recovery is predictable.

Many reports show that stuttering typically starts at 2-4 years of age, and most children who are destined to recover naturally will have done so by age 8 . Therefore, we also question Howell's assertion that he can predict stuttering recovery when children are 8 years old.

Mark Onslow, Ann Packman Australian Stuttering Research Centre, The University of Sydney, Australia.

mark.onslow@sydney.edu.au
Peter Howell replies: A comprehensive list of technical references to support my arguments (Nature 470, 7; 2011) is available at go.nature. com/pzlmgw. These relate to statistical issues and the Lidcombe programme; to why I hold that single-syllable whole-word repetitions should not be considered symptoms of stuttering; to my position that use of whole-word repetitions overestimates incidence rate; to why I contend that severity predicts risk of stuttering persistence; and to my view that the severity model can be used to predict persistence of stuttering beyond the age of eight (P. Howell and S. Davis J. Dev. Behav. Pediatr., in the press).

The reason why I pointed out that operant work originated in animal studies was to indicate that clinical studies could also benefit from examination of recent advances in animal operant work.

Peter Howell University College London, UK. p.howell@ucl.ac.uk

\section{Clarifying relatives and ancestors}

You twice erroneously describe the extinct woolly mammoth and American mastodon as ancient "ancestors" of today's elephants (see go.nature. com/q7fvk6 and go.nature. com/91a4zy).

They are actually fossil relatives of today's elephant species, as is made clear in the original research paper (N. Rohland et al. PLoS Biol. 8, e1000564; 2010) on which the two items report. With the extensive range of expertise at the disposal of your journal, I am surprised at these slips.

Walter Shearer Hartsdale, New York, USA.

wshearer@optonline.net 